\title{
POP-UP CARDS FOR EARLY CHILDHOOD LEARNING
}

\section{Marlina Shinta Putri, Siti Wahyuningsih, Ruli Hafidah}

Sebelas Maret University

marlinashintap@gmail.com

\section{Article History}

accepted 09/07/2018

approved 01/08/2018

published 17/09/2018

Keywords

Pop-up Cards, Early

Childhood

\begin{abstract}
The purpose of this study is to apply pop-up card in early childhood learning. This research used qualitative approach. The subjects in this research were children aged 4-5 years. Data collection techniques were conducted through interviews, observation, and documentation. Technique of validity test of qualitative data used triangulation technique and triangulation of source. The analysis technique for qualitative data used interactive model. The stages of application of pop-up card for early childhood learning include: (1) preparation stage, (2) implementation stage, and (3) the closing stage. The benefits of the application of pop-up cards for early childhood learning include: to facilitate the child in understanding the learning materials and make it easier for children to recognize letters and tell stories.
\end{abstract}

Social, Humanities, and Education Studies (SHEs): Conference Series https://jurnal.uns.ac.id/shes

p-ISSN 2620-9284 e-ISSN 2620-9292 


\section{PENDAHULUAN}

Pembelajaran untuk anak usia dini sebaiknya dikemas secara menyenangkan. Kegiatan pembelajaran yang menyenangkan dapat melalui penerapan media pembelajaran yang menarik minat dan perhatian anak. Penerapan media pembelajaran harus memperhatikan beberapa faktor, Anitah (2009) menjelaskan bahwa dalam pemilihan media pembelajaran harus mempertimbangkan beberapa faktor yaitu tujuan pembelajaran, pebelajar, ketersediaan, ketepatgunaan, biaya, mutu teknis, dan kemampuan SDM. Media pembelajaran yang digunakan dalam keseharian pada kegiatan pembelajaran di TK ABA Karanganom untuk kelompok usia 4-5 tahun berupa LKA pada majalah, papan tulis, buku tulis, dan buku gambar. Media pembelajaran yang digunakan sudah cukup banyak, namun guru mengharapkan media pembelajaran yang digunakan dapat membuat anak terlibat aktif dalam menggunakannya. Anak yang terlibat aktif dalam menggunakan media pembelajaran diharapkan anak mampu memahami pembelajaran dengan mudah.

Berdasarkan permasalahan tersebut, dapat diatasi dengan berbagai cara salah satunya dengan penggunaan media pembelajaran pop-up card. Barton (2005) mengungkapkan bahwa pop-up adalah gerakan otomatis menarik keluar dan menjauh dari halaman buku atau kartu saat dibuka. Kelebihan pop-up card menurut Hardjo, Retnowati, \& Rostikawati (2017) bahwa pop-up card dapat memberikan visualisasi cerita yang lebih menarik yang dimulai dari tampilan ilustrasi yang memiliki dimensi, gambar yang dapat bergerak, dan mampu berubah bentuk. Gregory (2016) menjelaskan bahwa pop-up card merupakan bentuk sederhana dari pop-up book. Hasil penelitian yang dilakukan oleh Yuliati, Suhartiningsih, \& Hidayati (2017) menunjukkan bahwa buku cerita pop-up dapat digunakan sebagai media pembelajaran dalam meningkatkan kemampuan bahasa anak dan meningkatkan minat baca mereka.

Pengertian media pembelajaran dari beberapa ahli yang ada dapat disimpulkan bahwa media pembelajaran adalah alat, metode, dan teknik yang digunakan untuk menyampaikan pesan antara guru dan anak agar dapat mencapai tujuan pembelajaran yang lebih baik dan sempurna. Salah satu manfaat media pembelajaran, yaitu untuk membantu guru dalam mengajar sehingga pesan yang ingin disampaikan kepada anak dapat dengan mudah dipahami oleh anak. Penggunaan media pembelajaran harus memperhatikan beberapa kriteria yang disimpulkan dari beberapa ahli seperti a) tujuan pembelajaran, b) pebelajar, c) harga, d) nilai kepraktisannya, dan e) mutu teknis.

Pop-up card adalah sebuah kartu ketika dibuka akan muncul suatu karakter. Hardjo, Retnowati, \& Rostikawati (2017: 1338) mengungkapkan bahwa kelebihan popup card dapat memberikan visualisasi cerita yang lebih menarik yang dimulai dari tampilan ilustrasi yang memiliki dimensi, gambar yang dapat bergerak, dan mampu berubah bentuk. Selanjutnya Putri, Yasbiati, \& Pranata (2018: 176) menjelaskan bahwa Pop-up card di desain dengan warna-warna yang menarik, bentuknya tiga dimensi, gambar-gambarnya menarik, unik, dan memberi kesan tersendiri sehingga anak akan lebih bersemangat mengikuti proses pembelajaran. Kemudian Tim Olvista (2011) menambahkan bahwa menariknya kartu pop up, maka kartu ini tidak hanya digunakan sebagai kartu ucapan saja tetapi juga bisa digunakan sebagai hiasan atau bahan edukasi bagi anak-anak. Berdasarkan penjelasan di atas dapat ditarik kesimpulan bahwa pop-up card memiliki beberapa kelebihan yaitu: menarik perhatian untuk belajar, meningkatkan semangat untuk belajar, dan bahan edukasi bagi anakanak. Pop-up card yang digunakan dalam penelitian ini adalah jenis pop-up parallel. Ives (2009: 11) pop-up parallel: jenis pop-up ini ketika membuka halaman dari buku atau kartu hanya terbuka setengah jalan atau sampai $90^{\circ}$ lalu muncul satu atau lebih lapisan gambar yang sejajar dengan latar belakang kartu. Peneliti membuat pop-up card model pararel fold karena untuk memudahkan dalam pengerjaan secara manual dan dapat memperjelas materi pembelajaran. 


\section{METODE}

Penelitian ini dilakukan di TK ABA Karanganom Klaten selama 6 bulan pada semester genap. Subjek dalam penelitian yaitu anak usia 4-5 tahun. Sumber data yaitu anak usia 4-5 tahun dan guru. Penelitian ini dengan pendekatan kualitatif. Teknik pengumpulan data dilaksanakan melalui wawancara, observasi, dan dokumentasi. Teknik uji validitas data kualitatif yang digunakan adalah triangulasi teknik dan triangulasi sumber. Teknik analisis data yang digunakan pada data kualitatif adalah analisis kualitatif model interaktif yan terdiri dari 4 tahap yaitu pengumpulan data, reduksi data, penyajian data dan penarikan kesimpulan.

\section{HASIL DAN PEMBAHASAN}

Pelaksanaan penelitian terdiri dari perencanaan, tindakan, pengamatan, dan refleksi. Data wawancara, observasi, dan dokumentasi dianalisis mengacu pada tindakan penerapan media pembelajaran pop-up card pada anak usia dini.

\section{Cara Membuat Media Pembelajaran Pop-up Card}

Pertama yang perlu di persipakan dalam membuat pop-up card yaitu menyiapkan alat dan bahan. Gregory (2016: 10) menjelaskan bahwa ada beberapa perlatan yang dibutuhkan untuk membuat pop-up card yaitu pensil, penggaris logam, penghapus, alat cetakan, papan garis, pisau kerajinan, dan alat penimbul lipatan. Sedangkan Birmingham (2010: 14-15) mengungkapkan bahwa bahan yang digunakan untuk membuat pop-up antara lain kartu, lem, gunting, pisau kerajinan, penggaris, pensil, alat penimbul lipatan, penghapus, peralatan meggambar, dan papan garis. Senada dengan Irvine (2008: 10) mengemukakan bahwa bahan yang diperlukan untuk membuat pop-up seperti kertas, gunting, pisau pemotong, penggaris, lem, peralatan menggambar (pensil, spidol, krayon, dan pensil warna), cat, pengencang kuningan, dan peralatan dekorasi (tali, karet gelang, kain, kancing, pita, bungkus kado, dan bulu). Terdapat banyak alat dan bahan yang digunakan untuk membuat pop-up card, peralatan yang digunakan antara lain: kertas, penggaris, pensil, penghapus, gunting, pisau kerajinan, lem, dan peralatan dekorasi. Kedua proses pembuatan sesuai dengan langkah-langkah dari Irvine (2008: 12) yang menjelaskan bahwa cara membuat popup sebagai berikut: a) Lipat kertas menjadi dua bagian dan potong tepi yang terlipat. b) Setelah memotong buat lipatan kuat dengan membuka lipatan garis menggunakan ibu jari dan telunjuk. c) Lebih mudah mendorong potongan kesisi lain jika memegang kertas seperti tenda. d) Tutup kertas dan tekan dengan kuat, bentuk yang dipotong akan tetap terdorong ke sisi lain kertas. e) Jangan sekali-kali menerapkan lem didekat bentuk pop-up f) Buat satu atau lebih segitiga lipatan pada paruh atau bagian mulut akan memberi beberapa bentuk yang sangat menarik. Rancang pop-up sendiri, dengan cara membuat potongan yang berbeda di tepi lipatan kertas yang terlipat dan dorong bentuknya ke sisi yang lain. Pop-up card yang dibuat yaitu jenis pararel fold.

Anitah (2009: 80) mengungkapkan bahwa dalam pemilihan media pembelajaran harus mempertimbangkan beberapa faktor yaitu tujuan pembelajaran, pebelajar, ketersediaan, ketepatgunaan, biaya, mutu teknis, dan kemampuan SDM. Secara ringkas Mursid (2015: 48) menambahkan bahwa faktor-faktor yang perlu diperhatikan dalam pemilihan media pembelajaran adalah a) komunikatif, b) harganya yang murah, c) nilai kepraktisannya, dan d) kondisi pemakaiannya. Selain faktor-faktor diatas Arsyad (2010: 75-76) menjelaskan bahwa ada beberapa kriteria yang patut diperhatikan dalam pemilihan media pembelajaran antara lain a) sesuai dengan tujuan yang ingin dicapai, b) tepat untuk mendukung isi pelajaran, c) praktis, luwes, dan bertahan, c) guru terampil menggunakannya, d) pengelompokkan sasaran, dan e) mutu teknis. Media pembelajaran pop-up card yang digunakan sudah sesuai dengan kriteria pemilihan media yaitu a) tujuan pembelajaran berupa isi dari pop-up card berisi objek yang sesuai dengan tema pembelajaran, b) pebelajar berupa disesuaikan 
dengan usia anak sehingga di design semenarik mungkin dengan memadukan beberapa warna, c) harga berupa membuat sendiri dengan menggunakan alat dan bahan yang terdapat disekitar lingkungan seperti kertas bisa bekas atau baru sehingga akan lebih murah, d) nilai kepraktisannya berupa pemilihan jenis pop-up card yang sederhana seperti pararel fold sehingga memudahkan dalam pembuatannya e) mutu teknis berupa ketahanan media agar media tahan lama maka dilapisi dengan isolasi bening agar tidak terkena air.

\section{Penggunaan Media Pembelajaran Pop-up Card}

Penggunaan media pembelajaran pop-up card dalam kegiatan pembelajaran dapat dibagi menjadi 3 tahapan yang terdiri dari:

1) Preperation stage (tahap persiapan)

Tahap persiapan yang dilakukan dengan cara membuat media pembelajaran popup card. Media pembelajaran pop-up card dibuat dalam bentuk pararel fold. Pembuatan dalam bentuk pararel fold dapat memudahkan guru dalam menyesuaikan tema pembelajaran dengan cara mengganti isi yang terdapat dalam pop-up card dengan materi pembelajaran sehingga dapat lepas pasang.

2) Implementation stage (tahap penerapan)

Penerapan media pembelajaran pop-up card jenis pararel fold yang digunakan dalam penelitian ini dengan cara membuka kartu hanya selebar $90^{\circ}$. Penerapan media pop-up card dalam kegiatan pembelajaran diadaptasi dari penerapan media big-book. Lynch (2008: 3-5) menjelaskan bahwa penerapan media big-book dengan penyerdehanaan sebagai berikut:

a) Membuat suasana nyaman kepada anak

b) Menunjukkan buku kepada anak

c) Memberikan pertanyaan kepada anak mengenai hal yang sedang di lihat anak

d) Mintalah anak-anak untuk mengekspresikan reaksi pribadi mereka terhadap buku itu.

e) Dengarkan baik-baik apa yang dikatakan dan dilakukan anak-anak

Berdasarkan penjelasan di atas mengenai penggunaan media big-book yang kemudian disesuaikan dengan media pop-up card sebagai berikut:

a) Menunjukkan pop-up card pada anak.

b) Memberitahu kepada anak cara penggunaan pop-up card dengan membuka kartu selebar $90^{\circ}$.

c) Memberikan pertanyaan kepada anak mengenai isi pop-up card yang sedang di lihat anak.

d) Meminta anak untuk menjawab pertanyaan dari guru.

e) Menerima jawaban dari anak dengan mendengar apa yang dikatakan dan dilakukan anak.

3) Closing stage (tahap penutup)

Guru memberikan penguatan materi pembelajaran kepada anak dengan cara tanya jawab kepada anak dan memberikan kesimpulan kepada anak.

Kegiatan pembelajaran saat penelitian dengan mengenalkan tema seperti alam semesta, anak terlihat begitu tertarik dengan memperhatikan objek yang terdapat didalamnya dan anak dapat menjelaskan objek tersebut dengan bahasa anak sendiri sehingga anak dapat memahami materi pembelajaran dengan mudah dan dapat meningkatkan kemampuan anak dalam bercerita. Kegiatan pembelajaran saat anak mengenal huruf, anak terlihat fokus dengan mengamati detail bentuk huruf yang dapat diraba, sehingga anak dapat memahami huruf dengan mudah terbukti anak dapat membedakan huruf dengan benar. Guru merasakan bahwa anak menunjukkan reaksi yang positif ketika anak menggunakan media pembelajaran pop-up card sehingga media pembelajaran pop-up card dapat memudahkan guru dalam menyampaikan pembelajaran 


\section{SIMPULAN}

Hasil penelitian dapat disimpulkan bahwa penggunaan media pembelajaran pop-up card dapat diterapkan dalam pembelajaran pada anak anak usia 4-5 tahun TK ABA Karanganom Tahun Ajaran 2017/2018. Tahapan penerapan media pembelajaran pop-up card diawali dengan tahap persiapan yaitu menyiapkan media pembelajaran pop-up card yang akan digunakan disesuaikan dengan tema pembelajaran. Tahap pelaksanaan dilakukan setelah anak memahami cara penggunaan media pembelajaran pop-up card yang dijelaskan oleh guru. Tahap penutup dilakukan penguatan pada materi pembelajaran yang disampaikan melalui media pembelajaran pop-up card.

Penerapan media pembelajaran pop-up card dapat meningkatkan kemampuan anak dalam bidang perkembangan kognitif yaitu anak dengan mudah memahami materi pembelajaran dan bidang perkembangan bahasa yaitu anak dapat mengenal huruf dan bercerita dengan mudah. Hal ini terjadi karena media pembelajaran pop-up card melibatkan anak secara aktif dalam menggunakannya. Tampilan dari pop-up card yang menarik mampu meningkatkan minat dan perhatian anak dalam belajar.

\section{DAFTAR PUSTAKA}

Anitah, S. (2009). Media Pembelajaran. Surakarta: Panitia Sertifikasi Guru Rayon 13 FKIP UNS Surakarta.

Arsyad, A. (2010). Media Pembelajaran. Jakarta: PT Raja Grafindo Persada.

Barton, C. (2005). The Pocket Paper Engineer. China: Main Choice International Development, Ltd.

Birmingham, D. (2010). Pop-Up Design and Paper Mechanics, How to Make Folding Paper Sculpture. East Sussex: GMC Publications, Ltd.

Gregory, E. (2016). Pop-Up Cards. USA: Walter Foster Publishing

Hardjo, F. N., Retnowati, R., \& Rostikawati, T. 2017. Model Pembelajaran Student Teams Achievement Divisions dengan Media Pop Up Card untuk Meningkatkan Hasil Belajar Biologi Kelas XI IPA 1 SMA Siliwangi Bogor. Pendidikan Sains Pascasarjana Universitas Negeri Surabaya, ISSN : 2089-1776, 6(2). Universitas Negeri Surabaya.

Irvine, J. (2008). How to Make Super Pop-Ups. Mineola, New York: Dover Publications, INC.

Ives, R. (2009). Paper Engineering \& Pop-Ups for Dummies. Canada: Wiley Publishing, INC.

Lynch, P. (2008). Using Big Books and Predictable Books. Canada: Scholastic Canada Ltd.

Mursid. (2015). Belajar dan Pembelajaran Paud. Bandung: PT Remaja Rosda Karya.

Putri, G. F., Yasbiati, \& Pranata, O. H. 2018. Pengaruh Media Pop-Up Card terhadap Hasil Belajar Siswa pada Materi Penggolongan Hewan berdasarkan Jenis Makanannya. Pedadidaktika: Jurnal Ilmiah Pendidikan Guru Sekolah Dasar, 5(1): 174-183. UPI.

Tim Olvista. (2011, 11 Mei). Apa itu Kartu Pop Up?. Diperoleh pada 4 Desember 2017, dari https://www.scribd.com/doc/213198737/Kartu-Pop-Up.

Yuliati, N., Suhartiningsih, \& Hidayati, L. (2017). The Development of Pop-Up Story Book for Improving Language Ability. The International Journal of Social Sciences and Humanities Invention, 4(8), 3750-3755. 